\title{
Effects of exergame training on the health promotion of young adults
}

\author{
Efeitos do treinamento com exergames na \\ promoção da saúde de adultos jovens
}

\section{Audrin Said Vojciechowski ${ }^{[a]}$, Jéssica Zampier Natal ${ }^{[a]}$, Anna Raquel Silveira Gomes ${ }^{[a]}$, Elisângela Valevein Rodrigues ${ }^{[\mathrm{b}]}$, Isabela Lúcia Pelloso Villegas ${ }^{[\mathrm{c}]}$, Raciele Ivandra Guarda Korelo ${ }^{[\mathrm{a}]^{*}}$}

[a] Universidade Federal do Paraná (UFPR), Curitiba, PR, Brazil

[b] Instituto Federal do Paraná (IFPR), Curitiba, PR, Brazil

[c] Faculdade Dom Bosco, Curitiba, PR, Brazil

\section{Abstract}

Introduction: Training with exergames has been prescribed for health problems prevention, however, little is known about its influence on the self-perception of the physical condition and on the physical and motor skills (PMS). Objective: To investigate the effects of exergames (EXG) on the self-perception of the physical condition, level of physical activity and PMS in healthy young adults. Methods: Forty young adults, of both genders, were allocated by convenience into Control Group (CG, $n=20,21.85 \pm 0.62$ years old), the individuals did not perform the physical training with exergames, and Intervention Group (IG, $n=20,23.10 \pm 0.61$ years old), the subjects practiced exergames training (XBOX360 Kinect $^{\circledR}$ ), in pairs, twice a week, for 12 weeks. Anthropometric measurements; self-perceived physical condition (International Fitness Scale-IFIS); International Physical Activity Questionnaire (IPAQ) and PMS (flexibility; abdominal endurance; upper limb strength and endurance, agility and velocity) were evaluated. Results: The IG presented better self-perception of the physical condition; increased physical activity level in the leisure domain and enhanced PMS after 12 weeks of intervention, compared to the CG. Conclusion: The EXG was efficient to improve skeletal muscle function, to contribute to physical exercise adherence and to promote physical health in active young adults.

Keywords: Video Game. Health Promotion. Exercise.

\footnotetext{
ASV: BS, e-mail: asaidvoj@gmail.com

JZN: BS, e-mail: jek_natal@hotmail.com

ARSG: PhD, e-mail: annaraquelsg@gmail.com

EVR: MS, e-mail: elisangela.rodrigues@ifpr.edu.br

ILPV, MS, e-mail: fisio.isabelavillegas@gmail.com

RIGK, PhD, e-mail: raciele@ufpr.br
} 


\section{Resumo}

Introdução: $O$ treinamento com exergames tem sido prescrito para prevenção em saúde, no entanto, pouco se sabe sobre sua influência na autopercepção da condição física e nas capacidades físico-motoras. Objetivo: Investigar os efeitos dos exergames (EXG) sobre a autopercepção da condição física, nível de atividade física (AF) e capacidades físico-motoras (CFM) de adultos jovens saudáveis. Métodos: Quarenta adultos jovens, de ambos os sexos, foram distribuídos por conveniência em Grupo Controle (GC, $n=20,21,85 \pm 0,62$ anos) que não realizou treinamento físico e Grupo Intervenção (GI, $n=20,23,10 \pm 0,61$ anos) que realizou treinamento físico com videogame (XBOX360 Kinect ${ }^{\circledR}$ ), em duplas, 2 vezes por semana, durante 12 semanas. A avaliação consistiu na verificação das medidas antropométricas; auto-percepção da condição física (International Fitness ScaleIFIS); nível de Atividade Física (AF, questionário IPAQ) e CFM (flexibilidade, resistência abdominal, força e resistência dos membros superiores agilidade e velocidade). Resultados: O GI apresentou melhora na autopercepção da condição física; aumento no nível de AF no domínio lazer e melhora nas CFM após 12 semanas de intervenção, em comparação com o grupo controle. Conclusão: $O$ EXG foi eficaz para incrementar a função musculoesquelética, favorecer a aderência ao exercício físico e promover a saúde física em adultos jovens ativos.

Palavras-chave: Videogame. Promoção da Saúde. Exercício.

\section{Introduction}

The practice of physical activity (PA) is necessary to maintain the physical and mental health of the individual at any age. The habit of performing PA should be acquired by children and adolescents, so that the benefits generated in the short-term influence the continuity of the practice of PA in adulthood (1). Adulthood and entry into the university contribute to changing behaviors, such as commencing work, undergoing intense biological changes, making new social relationships and experiencing psychosocial instability (2). It is considered that these factors can make people more vulnerable to health risk factors, since the lack of time to devote to physical exercises, the priority given to academic success and the unwillingness and/ or lack of motivation to perform some PA at the end of the day lead to the adoption of irregular habits in its practice or even a sedentary lifestyle (3).

Thus, Virtual Reality (VR) can be an alternative for young adults who cannot or do not wish to perform PA in the traditional way $(4,5)$. A proper term for this practice has not yet established in the scientific literature, with the terms "exergaming" (6) "virtual reality exercise" (7) "gaming-based virtual reality" (8), among others $(9,10)$ being found.

Exergames (EXG) require users to utilize physical and motor skills (PMS), such as: endurance, motor coordination, strength, balance and speed of movement (11); with its efficacy in improving these abilities in patients undergoing therapy having been proven, particularly in the recovery of upper limb function after a stroke (12) and improved gait and balance in older adults (10). However, few studies have verified the effects of EXG on healthy adult subjects $(10,12)$. Park, Lee and Lee $(7)$ found a significant improvement in muscular function of the lower limbs (LL) in healthy young adults, after 6 weeks of training (Nintendo Wii Fit ${ }^{\circledR}$ ), performed 3 times a week, for $40 \mathrm{~min}$. Furthermore, even when the practice of EXG was performed for a shorter duration (Nintendo Wii Fit ${ }^{\circledR} 3 \mathrm{x} /$ week for 25 minutes, total of 6 weeks), a trend of significant improvement in the stability of the trunk was verified (13).

Thus the aim of this study was to investigate the effects of a protocol of exercise through video games (XBOX360 Kinect ${ }^{\circledR}$ ) with exergames, on the self-perceived physical condition, PA level and physical and motor skills, in healthy adult university students.

\section{Methodos}

Sample

This was a nonrandomized, controlled clinical trial, with pre- and post-intervention evaluations conducted according to the Consolidated Standards of Reporting Trials (CONSORT) guidelines (14).

This study complied with the ethical principles contained in the Declaration of Helsinki of the World Medical Association. It was approved by the Research Ethics 
Committee of the Sector of Health Sciences of the Federal University of Paraná (CAAE 18541213.0000.7.0102), under Resolution 466/12 of the National Health Council and was registered in the Brazilian registry of Clinical Trials (RBR-69wpmz). All the participants signed the terms of consent.

A hundred and seventy five individuals were invited to participate in this study and those who were interested in participating and met the inclusion criteria were included. The inclusion criterias were: to be between 18 and 30 years old and to have a minimum frequency of participation greater than $75 \%$ (15). The exclusion criterias were: to have a chronic cardiovascular, musculoskeletal and/or neurological disease, to have undergone surgery in the year prior to the start of the study.

Participants of this study were 40 students of both genders, divided by convenience, according to the availability of time, into the Control Group (CG, $\mathrm{n}=20$, 13 females and 7 males, $21.85 \pm 0.62$ years old) and Intervention Group (IG, $\mathrm{n}=20,13$ female and 7 males $23.10 \pm 0.61$ years old). Members of the IG performed the EXG program for 12 weeks. Both groups were reevaluated after five weeks (W5) and after 12 weeks (W12). There was no withdrawal of any of the participants (Figure 1).

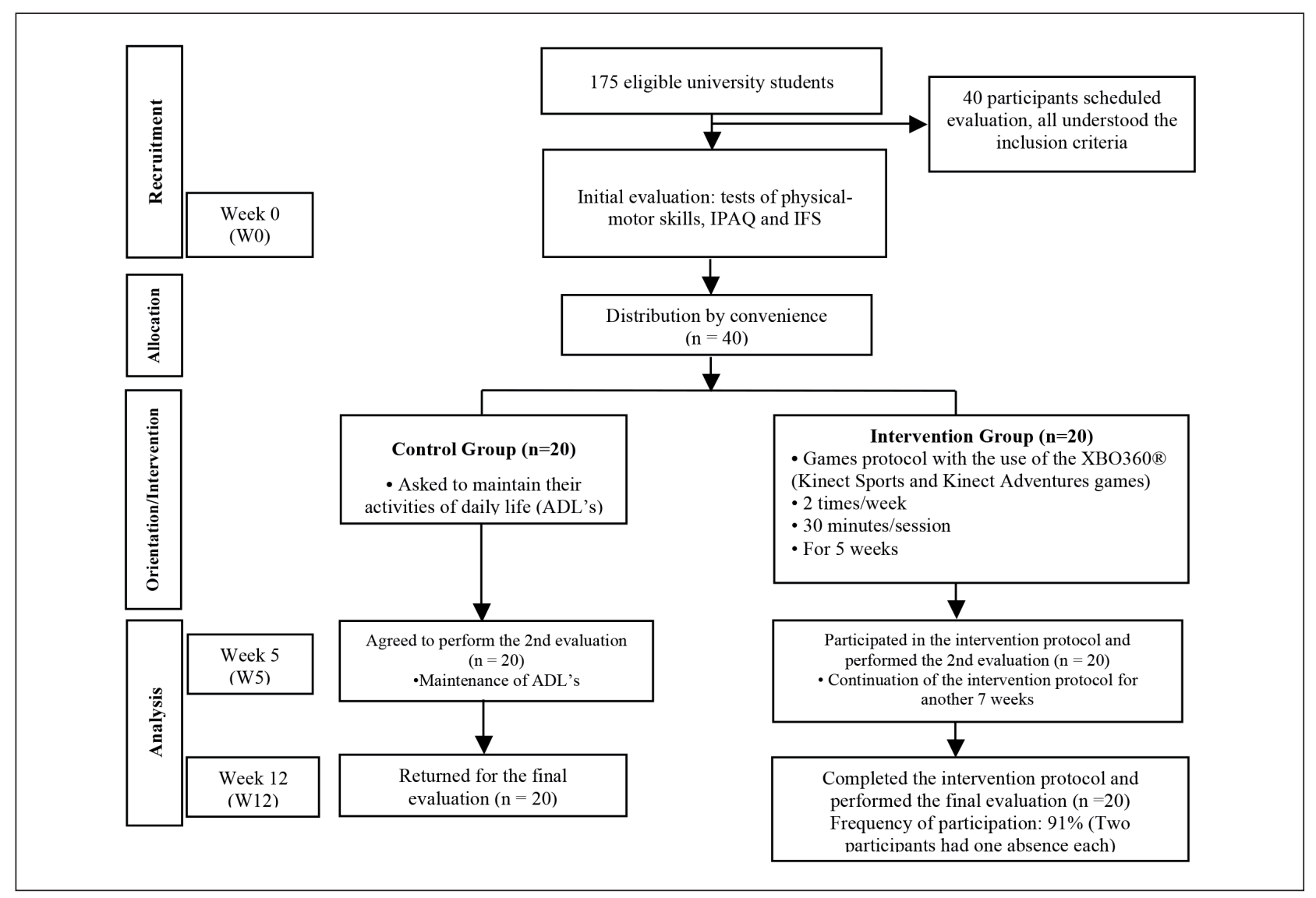

Figure 1 - Experimental design of the study.

\section{Anthropometric Measurements}

Body composition was obtained by measuring the body mass (kg), using a Cadence ${ }^{\circledR}$ digital scale, and height $(\mathrm{cm})$, using a millimeter tape measure fixed on a wall with no baseboard, with a length of 2 meters (16). Body mass index (BMI) was obtained by dividing the body weight by the square of the height $\left(\mathrm{kg} / \mathrm{m}^{2}\right)$ and classified according to the World Health Organization
(WHO) (17) as underweight (less than $18.5 \mathrm{~kg} / \mathrm{m}^{2}$ ), eutrophic (18.5 to $24.9 \mathrm{~kg} / \mathrm{m}^{2}$ ), overweight ( 25 to $29.9 \mathrm{~kg}$ / $\mathrm{m}^{2}$ ) and obese (greater than $30.0 \mathrm{~kg} / \mathrm{m}^{2}$ ). The Waist-Hip Ratio (WHR) was measured according to standards of the WHO (17), obtained by dividing the waist circumference (WC) by the hip circumference (HC), with values greater than $0.85 \mathrm{~cm}$ in women and $0.90 \mathrm{~cm}$ for men considered over the recommendations. 
Physical and Motor Skills (PMS)

To evaluate the PMS the following tests were performed: sit and reach test to measure the flexibility of the lower limbs (18); abdominal test to estimate abdominal strength and endurance (19); arm flexion test to assess strength and endurance of the upper limbs (UL) (20); shuttle run test to evaluate the agility and speed (21); and running 50 meters test to analyze the speed of movement (22).

Level of Physical Activity

The level of PA was assessed using the International Physical Activity Questionnaire (IPAQ), long version, validated in Brazil by Matsudo et al.(23). This questionnaire evaluates the intensity of the activity (walking, moderate activity, vigorous activity) and the time spent performing them in the week prior to the evaluation, with questions related to activities at work, at home, means of transport, leisure and time sitting.

The results obtained were calculated in minutes per week, following the recommendations proposed by the IPAQ Core Group (24) and the subjects were classified according to Silva et al. (25), considering the criteria of frequency and duration, as: sedentary, insufficiently active, active and very active.

\section{Perception of the physical condition}

For the analysis of self-perceived physical condition, the participants answered the International Fitness Scale (IFIS), covering questions about the physical condition, composed of five questions regarding general physical condition, cardiorespiratory fitness, muscle strength, speed-agility and flexibility in a 5-point Likert scale: very bad (1) bad (2) moderate (3), good (4) and very good (5). The Spanish version, translated and adapted to Portuguese (26) by 3 different Brazilian teachers of Spanish, was used.

\section{Exergame Program}

The EXG program was performed with the XBOX360 Kinect $^{\circledR}$, twice a week for 30 minutes, during 12 weeks. Participants performed the program in pairs, supervised by two researchers. Two games were used, one for each intervention, interspersing the Kinect Sports ${ }^{\circledR}$ and Kinect Adventures ${ }^{\circledR}$ games. The Beach Volleyball and Track and Field games of Kinect Sports ${ }^{\circledR}$ and the River
Rush and Reflex Ridge games of Kinect Adventures ${ }^{\circledR}$ were used.

The training was conducted with the participants standing in a large room, free of furniture or objects that could interfere with their performance. The difficulty level of the games was increased according to the performance of the pair during the interventions. The CG did not perform the EXG exercise program.

\section{Statistical Analysis}

The results are presented as mean and standard error. The data were submitted to the KolmogorovSmirnov test to test the normality of distribution. For the data that showed normal distribution intragroup differences before and after were analyzed using the paired Student's t-test and the differences between groups, evaluated at three moments (W0xW5, W5xW12, W0xW12), using Student's t-test for independent variables. For the data that did not show normal distribution, intragroup differences before and after were analyzed using the Wilcoxon test and the differences between groups using the Mann-Whitney U test. For the analysis of the IPAQ classification, Pearson's chi-square test was used. The Statistical Package for the Social Sciences (SPSS) software, version 22.0 for Windows, was used and the level of significance $p<.05$.

The effect size was determined through the calculation of $r$ according to Field (27), with $r=.10$ being considered a small effect, $r=.30$ a medium effect and values above .50 a large effect. The graphs were made in Microsoft Excel ${ }^{\circledR}, 2013$ version.

\section{Results}

All the participants of the IG completed the intervention protocol with greater than $91 \%$ attendance. There were no significant changes in intra and intergroup anthropometric measurements.

Regarding the results of the PMS (Table 1), there was no significant change for the CG in any of the five tests performed. The IG improved their physical capacities in the following tests: abdominal strength and endurance, the arm flexion, the shuttle run and the running 50 meters test in the three moments $(p<.05)$. Comparing to CG, the EXG increased the number of repetitions in the abdominal strength and endurance in the moments of W0xW5 ( $p=.00, r=.45)$ and W0xW12 ( $p=.00, r=.58)$; (increased the number of repetitions) to perform the 
arm flexion test in the moments of W0xW5 ( $p=.00, r=$ $.41)$ and W0xW12 ( $p=.00, r=.40)$; decreased the time to perform the shuttle run test in the moments W0xW5 $(p=.01 ; r=.38)$ and W0xW12 $(p=.00, r=.44)$; and increased the meters/second to accomplish the running
50 meters test in the moments W0xW5 ( $p=.00, r=.55)$ and W12xW0 ( $p=.00, r=.24)$. The differences found had sufficient magnitude (medium to large effect) to allow the assertion that the intervention protocol was able to improve PMS.

Table 1 - Physical and motor skills of the participants

\begin{tabular}{|c|c|c|c|c|c|c|c|}
\hline Variable & Group & Wo & $\begin{array}{l}\text { P-value } \\
\text { W0xW5 }\end{array}$ & W5 & $\begin{array}{l}\text { P-value } \\
\text { W5xW12 }\end{array}$ & W12 & $\begin{array}{l}\text { P-value } \\
\text { W0xW12 }\end{array}$ \\
\hline Sit and Reach (cm) & $\begin{array}{l}\text { CG } \\
\text { IG }\end{array}$ & $\begin{array}{l}31.90 \pm 1.9 \\
35.47 \pm 1.9\end{array}$ & .91 & $\begin{array}{l}31.80 \pm 1.8 \\
35.25 \pm 2.0\end{array}$ & .32 & $\begin{array}{c}31.90 \pm 1.8 \\
36.50 \pm 1.8^{* *}\end{array}$ & .45 \\
\hline Abdominal (repetitions) & $\begin{array}{l}\text { CG } \\
\text { IG }\end{array}$ & $\begin{array}{l}19.80 \pm 1.4 \\
21.00 \pm 0.9\end{array}$ & $.00^{*}$ & $\begin{array}{c}20.30 \pm 1.2 \\
24.45 \pm 1.4^{* *}\end{array}$ & .32 & $\begin{array}{c}20.95 \pm 1.1 \\
27.35 \pm 1.3^{* *}\end{array}$ & $.00^{*}$ \\
\hline Arm Flexion (repetitions) & $\begin{array}{l}\text { CG } \\
\text { IG }\end{array}$ & $\begin{array}{l}25.45 \pm 2.3 \\
27.85 \pm 1.8\end{array}$ & $.00^{*}$ & $\begin{array}{c}25.30 \pm 2.3 \\
32.80 \pm 2.2^{* *}\end{array}$ & .28 & $\begin{array}{c}27.05 \pm 1.9 \\
36.10 \pm 2.4^{* *}\end{array}$ & $.00^{*}$ \\
\hline Shuttle run (seconds) & $\begin{array}{l}\text { CG } \\
\text { IG }\end{array}$ & $\begin{array}{l}14.33 \pm 0.4 \\
14.31 \pm 0.6\end{array}$ & $.01^{*}$ & $\begin{array}{c}14.53 \pm 0.4 \\
13.09 \pm 0.4^{* *}\end{array}$ & .06 & $\begin{array}{c}14.35 \pm 0.4 \\
12.22 \pm 0.3^{* *}\end{array}$ & $.00^{*}$ \\
\hline 50 meters (meters/second) & $\begin{array}{l}\text { CG } \\
\text { IG }\end{array}$ & $\begin{array}{l}3.95 \pm 0.8 \\
3.82 \pm 0.8\end{array}$ & $00^{*}$ & $\begin{array}{c}3.82 \pm 0.8 \\
4.19 \pm 0.9^{\star \star}\end{array}$ & .10 & $\begin{array}{c}3.82 \pm 0.8 \\
4.39 \pm 0.9^{* \star}\end{array}$ & $.00^{*}$ \\
\hline
\end{tabular}

Note: $\mathrm{CG}=$ Control Group; IG=Intervention Group; W0=initial assessment; W5=evaluation after five weeks; W12=evaluation after 12 weeks. ${ }^{\star} p<.05$ for intergroup differences; ${ }^{* \star} p<.05$ for intragroup differences.

Analyzing the results of the IPAQ the EXG increased the amount of time spent on leisure activities compared to the CG between W0xW5 ( $p=.00, r=.63)$ and W0xW12 ( $p=.00, r=.79)$ (Figure 2).

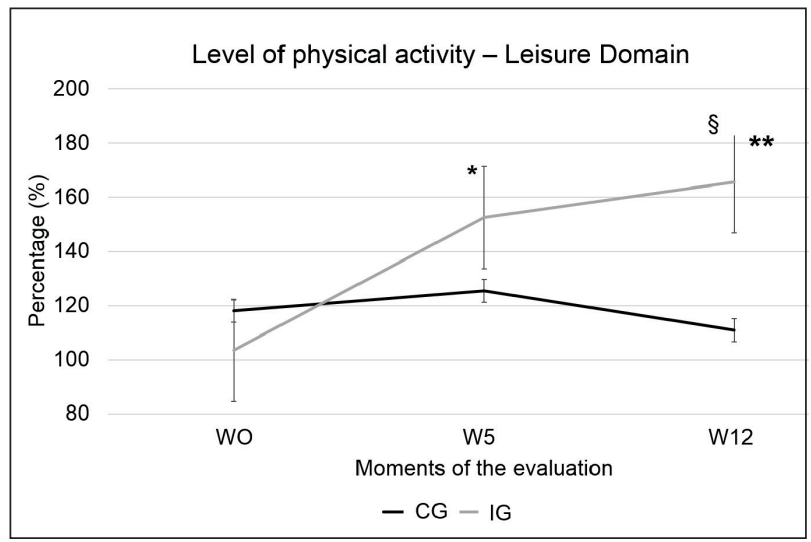

Note: $\mathrm{CG}=$ Control Group; $\mathrm{IG}=$ Intervention Group; $\mathrm{W} 0=$ initial assessment; $W 5=$ evaluation after five weeks; $W 12=$ evaluation after 12 weeks. ${ }^{*} p<.05$ for intergroup differences between W0xW5; ${ }^{\S}$ for intergroup differences between W5xW12 ${ }^{* *} p<.05$ for intragroup differences between W5xW12.

Figure 2 - Level of physical activity, according to the leisure domain of the IPAQ.
The IG showed decreased total time sitting, from $844.3 \mathrm{~min} /$ week to $724.1 \mathrm{~min} /$ week after 5 weeks ( $p=.01)$, however, with an increase after 12 weeks to $785.2 \mathrm{~min} /$ week, and therefore, compared to the control group, this significantly changed only between W5xW12 ( $p=.02, r=.50)$.

The majority of the participants in both groups were classified as active, regardless of the evaluation moment, however, there was no significant difference $(p>.05)$ between the groups in the three moments evaluated, despite of the higher percentage of individuals considered active in the IG (85\%) after 12 weeks.

The EXG provided significant improvement after 12 weeks (Table 2), in the self-perception of the general physical condition $(p=.04)$, strength $(p=.00)$ and speed/agility $(p=.00)$, however, did not change the self-perception of the cardiorespiratory fitness and flexibility $(p>.05)$ for the IG. However, comparing to $\mathrm{CG}$, only the self-perception of the speed improved after 12 weeks ( $p=.01 ; r=.55)$. 
Table 2 - Self-perceived health condition

\begin{tabular}{|c|c|c|c|c|c|c|c|}
\hline Variable & Group & Wo & $\begin{array}{l}\text { P-value } \\
\text { W0xW5 }\end{array}$ & W5 & $\begin{array}{l}\text { P-value } \\
\text { W5xW12 }\end{array}$ & W12 & $\begin{array}{c}\text { P-value } \\
\text { W0xW12 }\end{array}$ \\
\hline Physical condition & $\begin{array}{l}\text { CG } \\
\text { IG }\end{array}$ & $\begin{array}{l}3.05 \pm 0.1 \\
2.95 \pm 0.1\end{array}$ & .24 & $\begin{array}{l}2.95 \pm 0.1 \\
3.30 \pm 0.1\end{array}$ & 1.00 & $\begin{array}{c}3.05 \pm 0.1 \\
3.40 \pm 0.1 * \star\end{array}$ & .33 \\
\hline $\begin{array}{l}\text { Cardiorespiratory } \\
\text { Condition }\end{array}$ & $\begin{array}{l}\text { CG } \\
\text { IG }\end{array}$ & $\begin{array}{l}2.65 \pm 0.2 \\
2.60 \pm 0.2\end{array}$ & .92 & $\begin{array}{l}3.00 \pm 0.1 \\
2.75 \pm 0.2\end{array}$ & .05 & $\begin{array}{c}2.65 \pm 0.2 * * \\
2.85 \pm 0.1\end{array}$ & .09 \\
\hline Muscle strength & $\begin{array}{l}\text { CG } \\
\text { IG }\end{array}$ & $\begin{array}{l}3.30 \pm 0.2 \\
2.80 \pm 0.1\end{array}$ & .26 & $\begin{array}{c}3.30 \pm 0.1 \\
3.15 \pm 0.1^{\star \star}\end{array}$ & .33 & $\begin{array}{c}3.30 \pm 0.2 \\
3.35 \pm 0.1^{\star *}\end{array}$ & .14 \\
\hline Speed /agility & $\begin{array}{l}\text { CG } \\
\text { IG }\end{array}$ & $\begin{array}{l}3.20 \pm 0.2 \\
3.20 \pm 0.1\end{array}$ & .14 & $\begin{array}{c}3.25 \pm 0.2 \\
3.45 \pm 0.1^{\star \star}\end{array}$ & .11 & $\begin{array}{c}3.20 \pm 0.2 \\
3.70 \pm 0.1^{\star *}\end{array}$ & $.01^{*}$ \\
\hline Flexibility & $\begin{array}{l}\text { CG } \\
\text { IG }\end{array}$ & $\begin{array}{l}3.10 \pm 0.2 \\
2.85 \pm 0.2\end{array}$ & .14 & $\begin{array}{c}2.95 \pm 0.2 * \star \\
2.90 \pm 0.2\end{array}$ & .84 & $\begin{array}{c}3.10 \pm 0.2 \text { ** } \\
3.10 \pm 0.2\end{array}$ & .25 \\
\hline
\end{tabular}

Note: $\mathrm{CG}=$ Control Group; IG=Intervention Group; W0=initial assessment; W5=evaluation after five weeks; W12=evaluation after 12 weeks; ${ }^{*} p<.05$ for intergroup differences; ${ }^{* \star} p<.05$ for intragroup differences.

\section{Discussion}

This study demonstrated that physical training exergames performed twice a week increased the musculoskeletal function in just 5 weeks. In addition, there was an improvement in the level of PA and in the self-perception of the general physical condition after 12 weeks. The 91\% attendance of the participants in the IG was also noted, suggesting that this alternative training positively influenced the physical abilities evaluated.

Analyzing the results obtained in this study with regard to the influence of EXG on the PMS, significant improvement in the IG scores were observed at all moments of evaluation, except in the sit and reach test. In this study, after just five weeks of intervention, the participants of the IG had already significantly increase abdominal and upper limb strength and endurance, speed and agility, with even greater increases after 12 weeks of the intervention. It is suggested that these results are due to the games chosen that involved greater movement of the trunk, as they included, for example, lateral deviation and squat with trunk flexion movements.

A recent study (7) evaluated the effect of EXG on muscle activity of the trunk and lower extremities of healthy young adults, through surface electromyography before and after intervention with the Nintendo Wii $\mathrm{Fit}^{\circledR}$, three times a week, 40 minutes/session, for 6 weeks. The results found were not significant (7), however, in the present study was detected a tendency of EXG to improve the muscular function of the flexors and extensors of the trunk. In this study, increases in abdominal strength and endurance were verified after 5 and 12 weeks of the intervention.

In this study, the participants of the IG improved agility and speed. No other studies evaluating the agility and speed of young adults after an intervention with the VR were found. Thus, it can be suggested that the improvements of the PMS observed after training with EXG in healthy young adults may be due to the games chosen, as they allowed the simulation of sports practices using the lower limbs, such as athletics and volleyball, and with the Kinect Adventures ${ }^{\circledR}$ games, which required movements of the lower extremities for better performance. Another factor that may have influenced the improvement in the running tests was the competitive practice between the participants, for example, in the athletics that demanded greater speed in carrying out the stationary running.

Regarding the outcomes of lower extremity muscular activities, Park, Lee \& Lee (7) found a significant improvement in muscular function of the gastrocnemius and tibialis anterior after the intervention. The authors explained the results due to the games used (tennis, bowling and baseball), which required more movements of the lower limbs and less movements of the trunk muscles. Thus, these results may justify the increase in speed and agility found in the present study. Therefore, EXG performed only twice a week was sufficient to promote physical health in active young adults.

When considering the PA level, there was significant difference in the leisure domain presented by the IG in the intra and intergroup comparisons at the three evaluation moments. Considering the fact that the intervention proposed in this study was effective for 
increasing PA in the leisure domain, it could be assumed that the entertainment provided by the practice was a major stimulant for the participant to adhere to EXG and realize that health can be acquired in enjoyable activities. A narrative review (28) that evaluated the fun and pleasure during the practice of EXG found that the games provide physical and psychosocial benefits for the participants, due to the physiological effects caused by aerobic exercise and the fun generated by the game, which encourages the participant to perform better in order to beat their opponents and/or improve their scores in the game.

Regarding the final classification of the IPAQ 85\% of the participants in the IG was classified as "active", while $10 \%$ was classified as "very active" and only $5 \%$ as "insufficiently active" and no participant was classified as sedentary, at the end the 12 -week intervention program. In relation to the type of activity (walking, moderate and vigorous activity), the IG presented a significant increase in the duration of these activities. Accordingly, it can be supposed that even without having significantly changed the classification, the intervention with EXG provided changes in the PA habits of this sample, as well as encouraged them to spend less time sitting, decreasing the time sitting by approximately $55 \%$ in relation to the initial evaluation.

The validated study (29) of the IFIS questionnaire for young adults found positive results regarding the self-report of this sample in relation to their level of overall physical fitness and specific skills, suggesting that it is reliable and the test score corresponds to the skill tested. The outcomes of this study showed that the participants of the IG reported improved overall fitness and muscle strength, especially for speed/agility, with a large magnitude of effect $(r>.5)$ compared to the CG. These outcomes were very interesting because the self-perception of the individuals corroborated to the improvements observed in the muscular strength/endurance and speed/agility physical aspects. Furthermore, the adherence of the individuals to the training was 91\%. All these aspects show that EXG enhances adherence to train and that the increases in physical function are perceived by the individuals, constituting a health promotion strategy.

In the items related to cardiorespiratory fitness and flexibility, only the CG showed a significant difference in self-perception. Analyzing this possible improvement in the CG, it can be noted that the final measurement (W12) remained the same as the initial (W0), alternating only at the time of the second evaluation, suggesting that there was no improvement in self-perception, with a return to the initial perception.

Associated to this context, it is important to identify alternative methods for health promotion in this population, to encourage them to perform PA and to have reduced chances of developing chronic-degenerative diseases resulting from physical inactivity. Madureira et al. (30) reported that, despite the amount of information about PA and opportunities to perform them, few young adult university students are considered regularly active. Thus, exercise strategies that more effectively motivate this population should be developed, aiming to provide information about the benefits of PA and the impairments to health from physical inactivity.

Maciel et al. (31) reported that young adult university students were mostly physically active and had positive perceptions of the physical aspects related to health in their study. The authors also found an association between participation in PA programs when performed in groups and the active behavior. Incentives in the university environment were also reported by the participants as a way to enhance the benefits of PA and the technique for performing them, aiming to promote the health of this population and thus reduce the risk of developing diseases related to physical inactivity. Similarly, another study (32) found that EXG are an easy technique for practicing PA that motivate and entertain users and are available in the university environment, which could be a promising strategy of encouraging adherence to PA.

Besides, the proposed intervention protocol in this study promoted high adherence of the participants, with no withdrawals and the minimum frequency of participation greater than $91 \%$ (i.e., 22 of 24 days of the intervention). Some authors $(33,34)$ found that EXG can improve adherence to a PA program, as the practice provides increases in physical function that are noticeable to the individuals, thus becoming a strategy of health promotion. Finally, one study (34) suggests that in addition to the adherence during the study period, EXG can promote adherence to long-term practice of $\mathrm{PA}$, as new games continue to arouse motivation and provide enjoyment for users, as well as address the levels of physical skills for all ages.

The methodological limitations of this study are absence of follow up, randomization of the participants and monitoring the intensity of the training. Thus, it is suggested that in future studies a perceived exertion scale and heart rate monitors should be used to examine the intensity of the exercise. 


\section{Conclusion}

The practice of physical activity with the XBOX 360 Kinect $^{\circledR}$, performed twice a week for 30 minutes, provided improvement in the level of physical activity, self-perception of the health status and abdominal and upper limbs strength and endurance, agility and speed. Exergames can be used to promote health in active young adults.

\section{References}

1. Tavares LF, Castro IRR, Cardoso LO, Levy RB, Claro RM, Oliveira AF. Validade de indicadores de atividade física e comportamento sedentário da Pesquisa Nacional de Saúde do Escolar entre adolescentes do Rio de Janeiro, Brasil. Cad Saude Publica. 2014;30(9):1861-74.

2. Fontes ACD, Vianna RPT. Prevalência e fatores associados ao baixo nível de atividade física entre estudantes universitários. Rev Bras Epidemiol. 2010;12(1):20-9.

3. Gallardo-Escudero A, Alférez MJM, Pozo EMPP, Aliaga IL. La etapa universitária no favorece el estilo de vida saludable en las estudiantes granadinas. Nutr Hosp. 2015;31(2):975-9.

4. Staiano AE, Abraham AA, Calvert SL. Competitive versus cooperative exergame play for Afrin American adolescents' executive function skills: short-term effects in a long-term training intervention. Dev Psychol. 2012;48(2):337-42.

5. Baracho AFO, Gripp FJ, Lima MR. Os exergames e a educação física Escolar na cultura digital. Rev Bras Cienc Esporte. 2012;34(1):111-26.

6. Hung JW, Chou CX, Hsieh YW, Wu WC, Yu MY, Chen PC, et al. Randomized Comparison Trial of Balance Training by Using Exergaming and Conventional Weight-Shift Therapy in Patients With Chronic Stroke. Arch Phys Med Rehabil. 2014; 95(9):1629-37.

7. Park J, Lee D, Lee S. Effect of virtual reality exercise using the Nintendo Wii Fit on muscle activities of the trunk and lower extremities of normal adults. J Phys Ther Sci. 2014;26(2):271-3.

8. Choi JH, Han EY, Kim BR, Kim SM, Im SH, Lee SY, et al. Effectiveness of commercial gaming-based virtual reality movement therapy on functional recovery off upper extremity in subacute stroke patients. Ann Rehabil Med. 2014;38(4):485-93.
9. Monedero J, Lyons EJ, O'Gorman DJ. Interactive video game cycling leads to higher energy expenditure and is more enjoyable than convencional exercise in adults. PLoS One. 2015;10(3):e0118470.

10. Vaghetti CAO, Mustaro PN, Botelho SSC. Exergames no ciberespaço: uma possibilidade para Educação Física. SBC - Proceedings of SBGames. 2011 [cited 2015 Jun 14]. Available from: http://tinyurl.com/hb575yl.

11. Shin JH, Bog PS, Ho JS. Effects of game-based virtual reality on health-related quality of life in chronic stroke patients: A randomized, controlled study. Comput Biol Med. 2015;63:92-8.

12. Park EC, Kim SG, Lee CW. The effects of virtual reality game exercise on balance and gait of the elderly. J Phys Ther Sci. 2015;27(4):1157-9.

13. Lee D, Lee S, Park J. Effects of horseback riding and virtual reality exercises on the dynamic balance ability of normal healthy adults. J Phys Ther Sci. 2014;26(12):1903-5.

14. Schulz KF, Altman DG, Moher D, CONSORT Group. CONSORT 2010 statement: updated guidelines for reporting parallel group randomized trials. Ann Intern Med. 2010;152(11):726-32.

15. Mejia-Downs A, Fruth SJ, Clifford A, Hine S, Huckstep J, Merkel $\mathrm{H}$, et al. A preliminary exploration of the effects of a 6-week interactive video dance exercise program in an adult population. Cardiopulm Phys Ther J. 2011;22(4):5-11.

16. Jelliffe DB. The assessment of the nutritional status of the community. Geneva: WHO; 1966.

17. World Health Organization (WHO). Waist circumference and waist-hip ratio: report of a WHO expert soncultation. Geneva: WHO; 2008.

18. Moreira RB, Bergmann GG, Lemos AT, Cardoso LT, Nina GLD, Machado DT, et al. Teste de sentar e alcançar sem o banco como alternativa para a medida de flexibilidade de crianças e adolescentes. Rev Bras Ativ Fis Saude. 2009;14(3):190-6.

19. Albino J, Freitas CG, Martins VMS, Kanegusuku H, Roque TP, Bartholomeu T, et al. Tabelas de classificação da aptidão física para frequentadores de parques públicos. Rev Bras Med Esporte. 2010;16(5):373-7.

20. Marinho BF, Marins JCB. Teste de força/resistência de membros superiores: análise metodológica e dados normativos. Fisioter Mov. 2012;25(1):219-30. 
21. Souza J, Gomes AC, Leme L, Silva SG. Alterações em variáveis motoras e metabólicas induzidas pelo treinamento durante um macrociclo em jogadores de handebol. Rev Bras Med Esporte. 2006;12(3):129-34.

22. Arruda GA, Pianca HJC, Oliveira AR. Correlação do teste de 1RM com aspectos maturacionais, neuromotores, antropométricos e a composição corporal em crianças e adolescentes. Rev Bras Med Esporte. 2011;17(3):179-83.

23. Matsudo SM, Araújo T, Matsudo V, Andrade D, Andrade E, Oliveira LC, et al. Questionário Internacional de Atividade Física (IPAQ): estudo de validade e reprodutibilidade no Brasil. Rev Bras Ativ Fis Saude. 2001;6(2):5-18.

24. International Physical Activity Questionnaire. Guidelines for data processing and analysis of the international physical activity questionnaire (IPAQ): short and long forms; 2005.

25. Silva GSF, Bergamaschine R, Rosa M, Melo C, Miranda R, Bara Filho M. Avaliação do nível de atividade física de estudantes de graduação das áreas saúde/biológica. Rev Bras Med Esporte. 2007;13(1):39-42.

26. Ortega FB. The International Fitness Scale (IFIS): usefulness of self-reported fitness in youth. Int J Epidemiol. 2011;40(3):701-11.

27. Field A. Discovering statistics using IBM SPSS Statistics. 4th ed. London: SAGE; 2013.

28. Mellecker R, Lyons EJ, Baranowski T. Disentangling fun and enjoyment in exergames using an expandad desing, play, experience framework: a narrative review. Games Health J. 2013;2(3):142-9.
29. Ortega FB, Sánchez-Lopez M, Solera-Martínez M, Fernández-Sánchez A, Sjostrom M, Martínez-Vizcaino V.Self-reported and measured cardiorespiratory fitness similiary predict cardiovascular disease risk in young adults. Scand J Med Sci Sports. 2013;23(6):749-57.

30. Madureira AS, Corseuil HX, Pelegrini A, Petroski EL. Associação entre estágios de mudança de comportamento relacionados à atividade física e estado nutricional em universitários. Cad Saude Publica. 2009;25(10):2139-46.

31. Maciel ES, Vilarta R, Modeneza DM, Sonati JG, Vasconcelos JS, Vilela Junior GB, et al. The relationship between physical aspects of quality of life and extreme levels of regular activity in adults. Cad Saude Publica. 2013;29(11):2251-60.

32. Muñoz JE, Villada JF, Trujillo JCG. Exergames: una herramienta tecnólogica para la actividad física. Rev Med Risaralda. 2013;19(2):126-30. Spanish.

33. Warburton DER, Bredin SSD, Horita LTL, Zbogar D, Schott JM, Esch BTA, et al. The health benefits of interactive video game exercise. Appl Physiol Nutr Metab. 2007;32(4):655-63.

34. Biddiss E, Irwin J. Active video games to promote physical activity in children and youth. Arch Pediatr Adolesc Med. 2010;164(7):664-72.

Received in 11/06/2015

Recebido em 06/11/2015

Approved in 03/08/2016

Aprovado em 08/03/2016 
